\title{
Orbital granuloma: a rare manifestation of extrapulmonary tuberculosis
}

\author{
Nicolas Benech, ${ }^{1}$ Emmanuel Jouanneau, ${ }^{2,3}$ Christian Chidiac, ${ }^{1,3,4}$ Tristan Ferry $^{1,3,4}$
}

${ }^{1}$ Service de Maladies Infectieuses et Tropicales, Hôpital de la Croix-Rousse, Hospices Civils de Lyon, Lyon, France

${ }^{2}$ Service de Neurochirurgie B, Unité multidisciplinaire de

Chirurgie Tumorale de la base du Crâne, Hôpital

Neurologique Pierre Wertheimer, Hospices Civils de Lyon, Bron, France ${ }^{3}$ Université Claude Bernard Lyon 1, Lyon, France ${ }^{4}$ Centre International de Recherche en Infectiologie $(\mathrm{CIRI})$, Lyon, France

\section{Correspondence to} Dr Tristan Ferry, tristan.ferry@univ-lyon1.fr

Accepted 15 February 2016
CrossMark

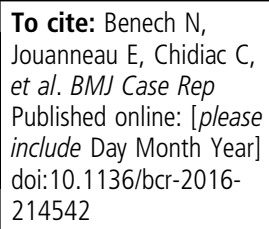

\section{DESCRIPTION}

An 86-year-old woman presented with a 2-year history of progressive right eye blindness associated with ocular retraction and ptosis, revealing an intraorbital nodule (figure 1A). She mentioned no other symptoms aside from initial ipsilateral purulent conjunctivitis, which resolved under local treatment. No fever, pulmonary symptoms or significant weight loss were reported. The patient's main medical history consisted of high-blood pressure, right retinal detachment 30 years previously, left hip replacement and binocular cataract surgery a few years prior. Neither she nor her relatives had a history of/or contact with tuberculosis. She had not travelled to any developing countries.

Despite the ophthalmological anomalies, physical examination did not present any abnormality: no adenopathies and no spinal or neurological anomalies. Brain MRI revealed a right orbital mass of $23 \times 23 \times 25 \mathrm{~mm}$ with contrast enhancement after gadolinium injection. Whole-body $18 \mathrm{~F}-$-fluorodeoxyglucose positron emission tomography scan showed

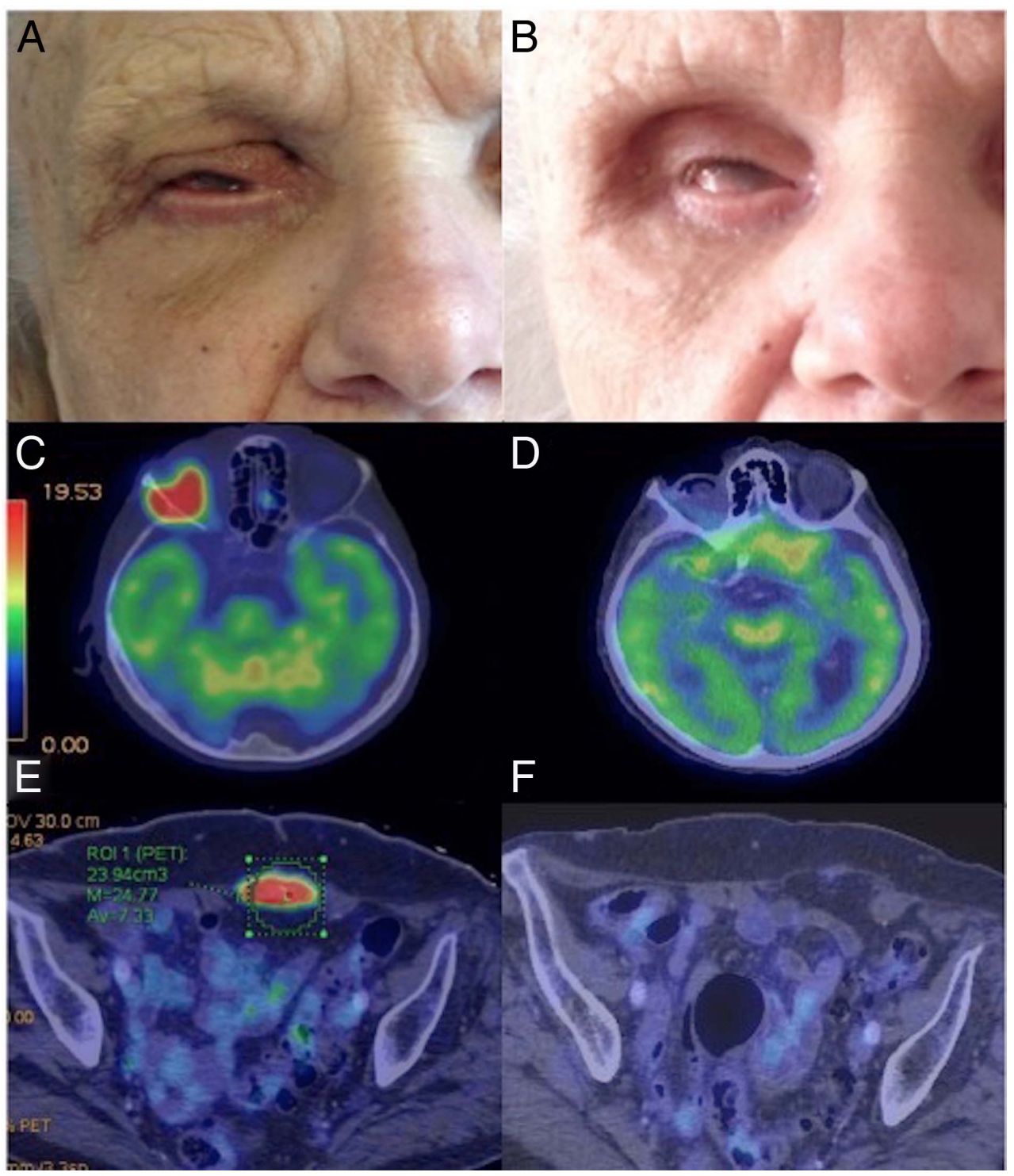

Figure 1 Clinical and radiological aspect of orbital tuberculoma before (left) and after 6 months of antituberculosis therapy (right): clinical aspect ( $A$ and $B)$ : enophthalmos, ptosis before $(A)$ and ocular retraction after treatment (B); 18F-FDG PET scan (C-F): orbital lesion (C) and peritoneal lesion (E) showing complete resolution after treatment (D and F). 18F-FDG PET, 18F-fluorodeoxy-glucose positron emission tomography. 
hypermetabolism at the orbital lesion (SUVmax, 33; figure 1C) and at another lesion facing the anterior peritoneum (SUVmax, 24; figure 1E). Thoracic CT was normal. Repeated interferon- $\gamma$ release test (QuantiFERON) and tuberculin skin test were negative, as were Bartonella, Rickettsia and HIV serology. CD4 count was $368 / \mathrm{mm}^{3}$ (32\%). Routine biochemistry and haematology, including $\mathrm{C}$ reactive protein, were normal. No lymphopenia was noted and no leucocytes were found in the urine. ACE was normal. Intraorbital biopsy was performed twice, revealing a giant cell granuloma with caseous necrosis. Two samples were cultured, without finding any mycobacteria. Nocardia PCR, 16S rRNA PCR, and common bacteriological and mycological cultures were sterile. Mycobacterial PCR was inconclusive.

Finally, a 6-month antituberculosis therapeutic trial was initiated, with a 2-month initial phase using isoniazid $(5 \mathrm{mg} / \mathrm{kg} /$ day), rifampicin (10 mg/kg/day), ethambutol (15 mg/kg/day) and pyrazinamide $(20 \mathrm{mg} / \mathrm{kg} /$ day $)$, followed by a 4 -month continuation phase (isoniazid and rifampicin). After 6 months of treatment, ocular retraction was observed (figure 1B); intraorbital and peritoneal lesions both resolved (figure 1D, F), but the patient remained blind in the right eye.

Orbital tuberculosis (OT) is an exceptional form of extrapulmonary tuberculosis. ${ }^{1}$ It can arise from haematogenous spread or local invasion through the paranasal sinuses. All orbital structures may be involved, from periostitis to dacryoadenitis. Usually, orbital cold tuberculoma has presenting features including proptosis, palpable orbital mass lesions and diplopia, but, as in the present case, orbital sclerosis with enophthalmos can also be found. Bone involvement should be screened for. Although OT is usually found in young patients, it can arise at any age. Synchronous tuberculosis lesions should be screened for as they are commonly found. Biopsy is usually performed. Diagnosis can be difficult to prove, even with modern immunological and molecular strategies, and treatment response can be taken as confirmation of aetiology. There is no consensus on duration of antituberculosis chemotherapy, but, because evolution is usually favourable, a 6-month treatment schedule is reasonable. Oral steroid therapy is rarely reported. Surgery may help in some cases. $^{2}$

\section{Learning points}

- Orbital tuberculoma is an uncommon form of extrapulmonary tuberculosis.

- Interferon- $\gamma$ release test (QuantiFERON) and tuberculin skin test could be negative in patients with extrapulmonary tuberculosis.

- Screening for synchronous tuberculosis lesions usually reveals other disease locations.

- Prognosis is usually good and standard 6-month antituberculosis therapy can be prescribed.

Contributors TF, EJ and CC participated in patient care, literature review and revision of the manuscript. NB participated in the literature review and wrote the manuscript.

Competing interests None declared.

Patient consent Obtained.

Provenance and peer review Not commissioned; externally peer reviewed.

\section{REFERENCES}

1 Madge SN, Prabhakaran VC, Shome D, et al. Orbital tuberculosis: a review of the literature. Orbit 2008;27:267-77.

2 Salam T, Uddin JM, Collin JRO, et al. Periocular tuberculous disease: experience from a UK eye hospital. Br J Ophthalmol 2015;99:582-5.

\footnotetext{
Copyright 2016 BMJ Publishing Group. All rights reserved. For permission to reuse any of this content visit

http://group.bmj.com/group/rights-licensing/permissions.

BMJ Case Report Fellows may re-use this article for personal use and teaching without any further permission.

Become a Fellow of BMJ Case Reports today and you can:

- Submit as many cases as you like

- Enjoy fast sympathetic peer review and rapid publication of accepted articles

- Access all the published articles

- Re-use any of the published material for personal use and teaching without further permission

For information on Institutional Fellowships contact consortiasales@bmjgroup.com

Visit casereports.bmj.com for more articles like this and to become a Fellow
} 